\title{
Application of Membrane Inlet Mass Spectrometry for Online and In Situ Analysis of Methane in Aquatic Environments
}

\author{
Michael Schlüter and Torben Gentz \\ Alfred-Wegener Institute for Polar and Marine Research, Bremerhaven, Germany
}

A method is presented for the online measurement of methane in aquatic environments by application of membrane inlet mass spectrometry (MIMS). For this purpose, the underwater mass spectrometer Inspectr200-200 was applied. A simple and reliable volumetric calibration technique, based on the mixing of two end member concentrations, was used for the analysis of $\mathrm{CH}_{4}$ by MIMS. To minimize interferences caused by the high water vapor content, permeating through the membrane inlet system into the vacuum section of the mass spectrometer, a cool-trap was designed. With the application of the cool-trap, the detection limit was lowered from 100 to $16 \mathrm{nmol} / \mathrm{L} \mathrm{CH}_{4}$. This allows for measurements of methane concentrations in surface and bottom waters of coastal areas and lakes. Furthermore, in case of membrane rupture, the cool-trap acts as a security system, avoiding total damage of the mass spectrometer by flushing it with water. The Inspectr200-200 was applied for studies of methane and carbon dioxide concentrations in coastal areas of the Baltic Sea and Lake Constance. The low detection limit and fast response time of the MIMS allowed a detailed investigation of methane concentrations in the vicinity of gas seepages. (J Am Soc Mass Spectrom 2008, 19, 1395-1402) ( 2008 American Society for Mass Spectrometry

$\mathrm{T}$ The analysis of methane as well as other trace gases like carbon dioxide, nitrous oxide, or dimethyl sulphide in aquatic environments is a major objective of basic and applied research. This includes investigations of the air-sea exchange of these greenhouse gases as well as of the release of methane from gassy sediments, hydrocarbon reservoirs, and pipelines, or through dissociation of gas hydrates. Although the spatial extent of such discharge sites is often rather small, ranging from a few square meters to several square kilometers, they are considered major drivers for the marine methane cycle in the present and past [1-4].

The localization of such discharge sites as well as the detection and quantification of trace gases in lakes or the ocean relies essentially on water sampling (e.g., by Rosette Water Samplers, Hydro-Bios, Kiel, Germany) and subsequent chemical analysis by gas chromatography $(\mathrm{GC})$ or infrared-spectrometry (IR) onboard the research vessel. Application of GC as well as IR requires the phase transfer of gases from the dissolved to the gaseous phase. For this purpose, head-space techniques, vacuum-degassing, or spray chambers are applied [5].

Head-space techniques and vacuum-degassing are very suitable for analysis of discrete water samples but

Address reprint requests to Dr. M. Schlüter, Alfred-Wegener Institute for Polar and Marine Research, Am Handelshafen 11, 27570 Bremerhaven, Germany. E-mail: mschlueter@awi-bremerhaven.de require considerable time for phase separation and chemical analysis. Only the application of spray chambers, pioneered by Weiss [6] and Weiss et al. [7], allows continuous online measurements of gases like $\mathrm{CO}_{2}$, $\mathrm{CH}_{4}$, or $\mathrm{N}_{2} \mathrm{O}$ in surface waters sampled along transects by research vessels. Nevertheless, the time required for equilibration and subsequent GC or IR analysis is about several tens of minutes to hours [7]. Hence, highresolution investigations, in time and space, of trace gases at natural gas seepages like pockmarks (morphological depressions at the seafloor) or hydrocarbon leakages during surveys by research vessels are rather difficult and time consuming.

Compared with such rather long measuring times, application of membrane inlet mass spectrometry (MIMS) for analysis of gases in aquatic environments allows the quantification of a multitude of gases on a time scale of a few seconds. Whereas in environmental research MIMS is very successfully applied in soil science or in studies on microbial turnover processes (e.g. [8-13]), it is a rather new application in marine and limnic research. Studies by Tortell [14] of $\mathrm{O}_{2}$, DMS or $\mathrm{N}_{2}$ concentrations in surface waters or by Hartnett and Seitzinger [15], investigating nitrogen concentrations in sediment cores, underlined the suitability of MIMS for geochemical investigations of marine and limnic environments.

Fast technical developments in the field of harsh environment mass spectrometry (HEMS) allow for mea- 
suring a wide range of gases by MIMS on board of small research vessels or even on mobile underwater platforms like autonomous underwater vehicles (AUVs) or submersibles [16, 17]. For this purpose, specific membrane inlet systems and underwater mass spectrometer (UWMS) such as the Inspectr200-200, the THETYS, or the NEREUS [16-23] were designed. These UWMSs can be operated in water depths of several hundred meters.

Compared with water sampling and analysis onboard ship, in situ gas analysis by UWMS is unaffected by degassing of samples due to depressurization during the ascent of the water sampler to the sea surface, as observed at gas hydrate sites off Oregon, for example, [24] and support chemical mapping of discharge sites due to the fast response time of MIMS. Therefore, application of UWMSs opens new research fields allowing quantification of a wide range of gases including carbon dioxide, methane, higher hydrocarbons, dimethyl sulphide, nitrogen, argon, as well as volatile organic compounds on a time scale of a few seconds.

A major objective of this study is the online analysis of methane in aquatic systems by application of membrane inlet mass spectrometry. Whereas a few studies applied MIMS for analysis of $\mathrm{CO}_{2}, \mathrm{O}_{2}$, or DMS concentrations in marine environments, or considered relative shifts of peak intensities indicative for $\mathrm{CH}_{4}$ concentrations [14, 16, 17], the calibration of an UWMS for measurement of methane concentration in coastal areas and lakes is a rather new topic. For this purpose, we applied the Inspectr200-200 (AML) underwater mass spectrometer. Whereas our first field trials with the UWMS in bottom waters of the eastern Baltic Sea revealed significant variations of carbon dioxide and oxygen concentrations with water depth, the detection limit of the system was insufficient for detailed studies of $\mathrm{CH}_{4}$ concentrations. Therefore, we reconsidered the calibration scheme and minimized interferences due to the high water vapor content within the membrane inlet systems. For this purpose, a cool-trap system was designed.

Applying these means, the detection limit for $\mathrm{CH}_{4}$ was lowered from $\sim 100$ to less than $16 \mathrm{nmol} / \mathrm{L}$. This enables investigations of methane concentrations in surface waters of coastal regions or lakes. In addition, the cool-trap system improves some inherent difficulties associated with underwater mass spectrometry, like the high water vapor content within the membrane section or the total damage of the system in case of a membrane failure.

\section{Methods}

\section{Underwater Mass Spectrometer: Inspectr200-200}

The Inspectr200-200 (AML) consist of a membrane inlet system, an Inficon (Bad Ragaz, Switzerland) Transpector CPM 200 quadrupole mass spectrometer, a Varian (Palo Alto, USA) turbo pump, a roughing pump, a gear pump, as well as an embedded PC and a micro- controller. An atomic mass-to-charge ratio $(\mathrm{m} / \mathrm{z})$ of 1 to 200 is covered by the Transpector CPM 200.

During operation of the Inspectr200-200, water is pumped by the gear pump from the outside into the pressure housing through the membrane inlet system (MIS) where gas permeation takes place, and back into the water column. Within the MIS, the water is in contact with a polydimethylsiloxane (PDMS) tubular membrane.

Through a $1 / 16$ in. capillary, the PDMS membrane is coupled to the high vacuum section and maintained at a typical pressure level of less than $10^{-5}$ Torr with the turbo pump. To avoid the collapse of the PDMS tube under hydrostatic pressures of up to 20 bar (equivalent to ca. $200 \mathrm{~m}$ water depths), the membrane is supported at the inside by a stainless steel spring. Gases permeating through the PDMS membrane are detected by the Inficon CPM 200 residual gas analyzer.

To ensure constant and reproducible physicalchemical conditions for the gas transfer through the membrane, the flow rate of water is controlled by the gear pump, and the membrane inlet system includes a heater and a thermocouple. The flow rate of water and the temperature of the MIS is adjusted and regulated by a micro-controller. We operated the MIS at a constant temperature of $50{ }^{\circ} \mathrm{C}$ and applied a constant flow rate of $3 \mathrm{~mL} / \mathrm{min}$.

According to Lloyd and Scott [25], $\mathrm{CH}_{4}, \mathrm{~N}_{2}, \mathrm{O}_{2}, \mathrm{Ar}$, and $\mathrm{CO}_{2}$ were quantified by the ion current detected at $\mathrm{m} / \mathrm{z}$ ratios of $15,28,32,40$, and 44 , respectively. Each $1.3 \mathrm{~s}$ a dataset is recorded. A detailed consideration of the Inspectr200-200 is given by Short et al. [16, 26] and about the gas permeation within the membrane inlet system by Bell et al. [23].

\section{Gas Chromatography}

As part of the calibration procedure of the Inspectr200200 and during field studies, methane concentrations of water samples were analyzed by gas chromatography. For this purpose, a Thermo Finnigan (Waltham, USA) TraceGC equipped with a flame-ionization detector and a Porapak Q column was applied. The water samples were transferred into $22 \mathrm{~mL}$ head space vials and crimped tightly. A head space of $5 \mathrm{~mL}$ volume was generated by inserting argon or nitrogen gas. After at least 5 hours of equilibration, the gas concentration in the head space was analyzed by gas chromatography. Based on the methane concentration in the head space and the $\mathrm{CH}_{4}$ concentration in the aqueous phase, which was computed by the Bunsen coefficient according to Wiesenburg and Guinasso [5], the methane concentration in the water sample was derived.

\section{Field Applications}

During cruises with R. V. Heincke to the Mecklenburger Bay (Baltic Sea) and R. V. Kormoran on Lake Constance (located in the tri-nation region of Germany, Switzer- 
land, and Austria), gas concentrations in water samples were analyzed. During these cruises, the Inspectr200200 was operated onboard ship for online analyses of water samples gathered along transects as well as at distinct sites of gas seepage.

For online analyses of surface waters, the mass spectrometer was coupled to the seawater intake system of the research vessel. On R. V. Heincke and R. V. Kormoran, surface waters were pumped from a depth of 3.5 and $1.5 \mathrm{~m}$ below sea surface, respectively. At sites where gas seepage from the seafloor was expected, we obtained water samples with a submersible pump (SQE2115, Grundfos, Bjerringbro, Denmark). The pump was lowered by the winch of the ship to water depths of up to $80 \mathrm{~m}$ and operated at a flow rate of more than $>2300 \mathrm{~L} / \mathrm{h}$. The delay time between sampling at depth and analysis by the mass spectrometer is less then 3 to $6 \mathrm{~min}$ due to the high pump rate.

During a cruise to the Mecklenburg Bay (W-Baltic Sea), the Inspectr200-200 was deployed to water depths of up to $15 \mathrm{~m}$ for in situ measurements of $\mathrm{CO}_{2}$, $\mathrm{O}_{2}$, and $\mathrm{CH}_{4}$. Together with a solid-state $\mathrm{CH}_{4}$ sensor (Franatech, Luneburg, Germany) and an optical methane analyzer (Contros, Kiel, Germany), the Inspectr200-200 was installed on a deployment frame and lowered by the winch of the research vessel (Figure 1).

\section{Calibration of the Inspectr 200-200}

Aqueous solutions containing defined gas concentrations of, e.g., methane, oxygen, or carbon dioxide are required for the calibration of membrane introduction mass spectrometers. Such solutions can be generated by purging commercially available standard gases like $0.1 \mathrm{vol} \%, 1.0 \mathrm{vol} \%$, or $10 \mathrm{vol} \% \mathrm{CH}_{4}$ through water until the equilibrium concentration is reached. Unfortunately, gas standards are often available in rather coarse concentration grades. This allows detailed calibration of gas chromatographs since differ-

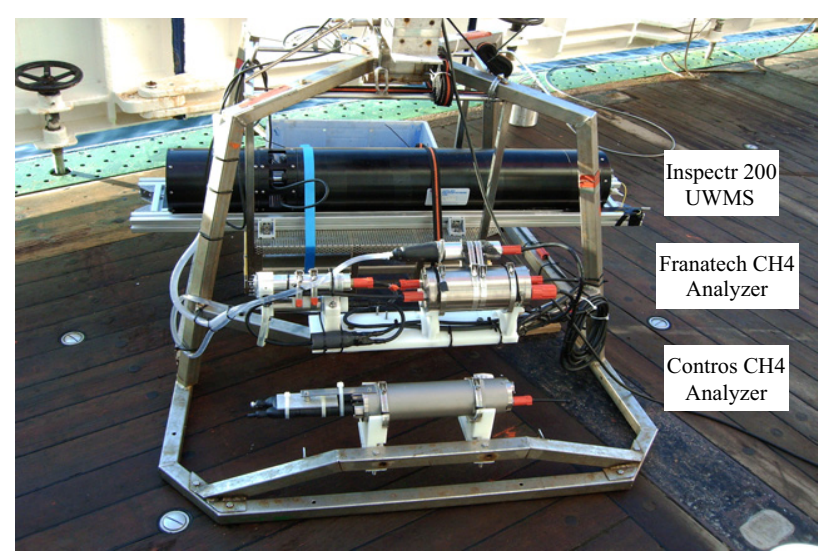

Figure 1. Deployment of the Inspectr200-200 underwater mass spectrometer together with a solid-state $\mathrm{CH}_{4}$ analyzer and an optical $\mathrm{CH}_{4}$ sensor in Mecklenburg Bay (W-Baltic Sea). ent volumes of each standard gas can be injected into the GC. In contrast, for a detailed calibration of a MIMS, the application of such a limited number of standards with very different concentrations seemed suboptimal.

As an alternative, we considered a technique widely applied for the analysis of gases in air, soils, or for quality control issues. In such applications, different standard gases are mixed with synthetic air or pure nitrogen by mass flow controllers. For the preparation of aqueous $\mathrm{CH}_{4}$ standards we applied $0.1 \mathrm{vol} \%$ as well as $1 \mathrm{vol} \% \mathrm{CH}_{4}$ standard gas (Air Liquid, Germany) and mixed it with $\mathrm{N}_{2}$ gas in different proportions by a Sensitron (Cornarado, Italy) CMOSens mass flow controller. The concentration of each gas admixture was carefully controlled by gas chromatography, which revealed constant concentrations over time.

Each gas admixture was injected into a water filled vessel (volume of $5 \mathrm{~L}$ ) with an air diffuser to produce an aqueous standard solution for $\mathrm{CH}_{4}$ calibration. This standard solution was analyzed by the Inspectr200-200 and sampled by head space vials for subsequent measurements by GC. Unfortunately, the GC analysis revealed significant fluctuations of $\mathrm{CH}_{4}$ concentrations over time. Although we applied different types of air diffusers, the temporal variation of the gas concentration was still significant.

As an alternative procedure, we generated two end member concentrations: (1) a $5 \mathrm{~L}$ water-filled flask equilibrated continuously with a $\mathrm{CH}_{4}$ standard gas (e.g., $0.1 \mathrm{vol} \%, 1 \mathrm{vol} \%$ or $10 \mathrm{vol} \%$ ) and (2) a $5 \mathrm{~L}$ water-filled flask freed of methane by continuously flushing with nitrogen or air. These two solutions were mixed in various proportions by a 12 channel peristaltic pump, merged by a T-piece and pumped via a column filled with glass beads (for mixing both solutions, carefully) into the membrane inlet system of the Inspectr200-200.

This volumetric technique for admixture of defined $\mathrm{CH}_{4}$ concentrations in aqueous solution was controlled by head space technique and gas chromatography. The GC analysis showed for each admixture constant and reproducible methane concentrations over periods of several hours. Based on one standard gas (e.g., $0.1 \mathrm{vol} \% \mathrm{CH}_{4}$ ), we generated up to 12 standard solutions with well-defined methane concentration (covering a concentration range of 70 to $830 \mathrm{nmol} / \mathrm{L}, 50$ to $9960 \mathrm{nmol} / \mathrm{L}$, and 2120 to 125,000 $\mathrm{nmol} / \mathrm{L}$, respectively) for studies about the signal to noise ratio, response time as well as for the calibration of the MIMS.

Furthermore, such standard solutions were transferred to gas tight sampling bags (Calibrated Instruments, Cali Bond, Hawthorne, USA) and used as reference solutions during measurements with the Inspectr200-200 onboard ship. Again, parallel to measurement with the MIMS we sampled the water into head space vials for subsequent analysis by GC. 


\section{Results and Discussion}

\section{Calibration of the MIMS for Analysis of Methane in Surface and Bottom Waters}

A wide range of methane concentrations are observed in aqueous environments. Low $\mathrm{CH}_{4}$ concentrations of less than $4 \mathrm{nmol} / \mathrm{L}$ have been reported for surface waters of the open ocean, whereas $\mathrm{CH}_{4}$ concentrations of more than $1000 \mathrm{nmol} / \mathrm{L}$ have been reported for coastal regions or estuaries (e.g., [27, 28]).

Although mass spectrometry is able to cover such a wide range of concentrations, the detection limit we obtained during the calibration of the Inspectr200-200 exceeded $100 \mathrm{nmol} / \mathrm{L} \mathrm{CH}_{4}$. Even for methane-free solutions, peak intensities of more then $2.3 \times 10^{-10}$ ampere were observed at $\mathrm{m} / \mathrm{z} 15$. Tuning of settings like the ionization voltage, the gain or the pump rate and temperature of the membrane inlet system revealed insignificant reductions in the intensity detected at $\mathrm{m} / \mathrm{z}$ 15 during analyses of methane-free solutions. The high background intensities seemed to be caused by the high water vapor content (detected at $\mathrm{m} / \mathrm{z} 18$ ), permeating through the PDMS membrane and affecting the intensities recorded at $m / z 15$.

To reduce such interferences, we dismounted the membrane inlet system from the mass spectrometer unit, inserted a 1/16 in. stainless steel capillary into this part of the vacuum section and cooled the capillary down to a temperature of -90 to $-80{ }^{\circ} \mathrm{C}$ by liquid ethanol. The ethanol was cooled down to this temperature by liquid nitrogen or a cooler (Lauda, RP890, Lauda-Königshofen, Germany).

This temperature is sufficient to strip the water vapor from the gas stream within the vacuum section at pressures of less than $10^{-5}$ Torr. As a consequence, the total ion current, the signal to noise ratio as well as the intensities detected at $\mathrm{m} / \mathrm{z} 15$ for methane free water samples were reduced significantly (Figure 2).

Comparing the calibration curves determined without and by application of the cool-trap (Figure 3) reveal similar regression coefficients and slopes, whereas a considerably lower intercept is observed when the cool-trap is applied. The application of the cool-trap allowed the calibration of the system for low $\mathrm{CH}_{4}$ concentrations (Figure 3a). Based on the calibration curve and replicate measurements of methane free solutions, a detection limit of $16 \mathrm{nmol} / \mathrm{L} \mathrm{CH}_{4}$ was derived. By implementing the cool-trap, the detection limit was therefore improved by a factor of five.

Besides the calibration procedure based on the volumetric mixture of well defined standard solutions, we analyzed the $\mathrm{CH}_{4}$ concentrations of water samples, parallel to the Inspectr200-200 measurements, through head-space technique and gas-chromatography. Results of this cross-validation are shown in Figure 4. A close correlation between results obtained by these two independent techniques is observed.
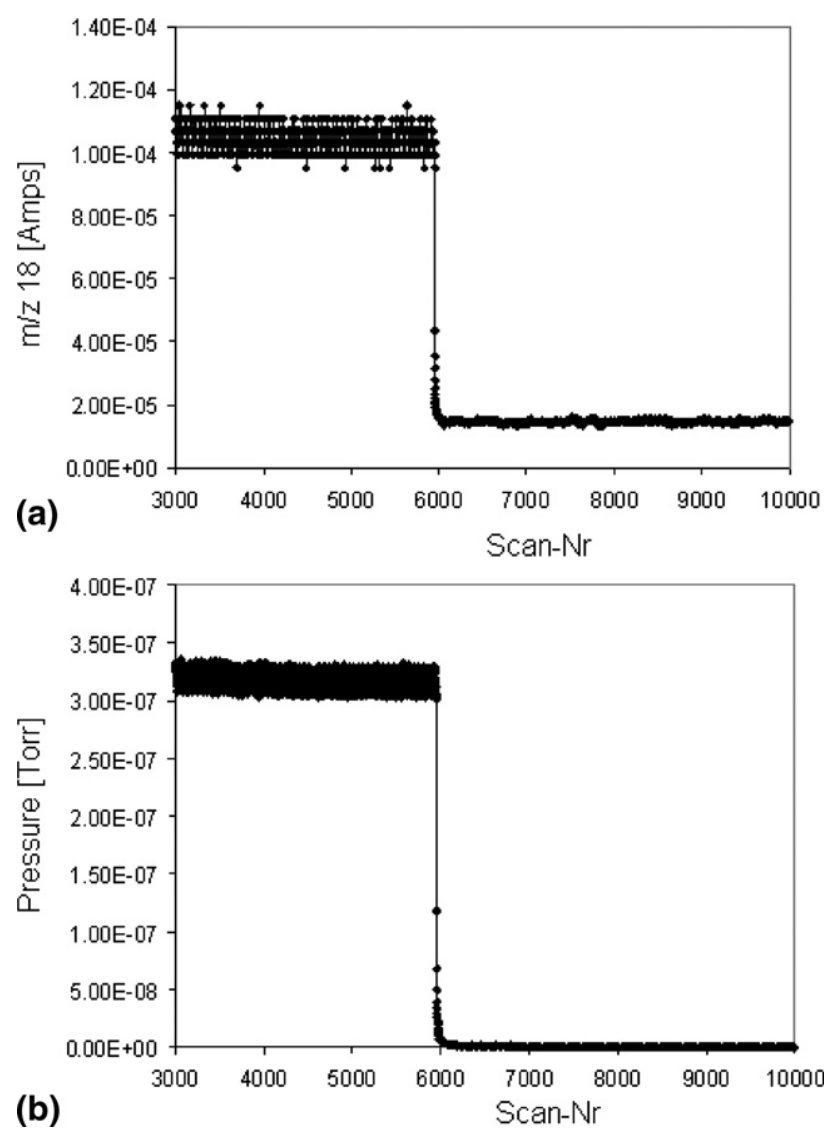

Figure 2. Implementation of the cool-trap (operated at -90 to $-80^{\circ} \mathrm{C}$ ) caused a significant reduction of (a) the water vapor content, permeating through the PDMS tubular membrane. By this means (b), the total pressure within the mass spectrometer as well as the signal to noise ratio at e.g., $\mathrm{m} / \mathrm{z} 15$ was considerably reduced.

Furthermore, the cool-trap provides a kind of security system in case of a potential rupture of the PDMS membrane, which would cause the complete flushing of the system with water and the total damage of the UWMS. In such an accident, the seawater flowing through the $1 / 16$ in. capillary is instantaneously frozen within the cool-trap. This provides us with sufficient time to switch off a high vacuum solenoid valve and to block the vacuum section of the mass spectrometer against the inflow of water.

\section{In Situ Measurements of $\mathrm{CO}_{2}, \mathrm{O}_{2}$, and $\mathrm{CH}_{4}$ in the} Baltic Sea

During a cruise with R. V. Heincke (HE260) to the Baltic Sea, the Inspectr200-200 was applied for in situ analyses of $\mathrm{CO}_{2}, \mathrm{O}_{2}$, and $\mathrm{CH}_{4}$ in bottom waters of the coastal region off the Mecklenburg Bay (W-Baltic Sea, water depth $\sim 20 \mathrm{~m}$ ). For this region, enhanced $\mathrm{CH}_{4}$ concentrations in the water column were expected [29].

During the deployment of the Inspectr200-200, the analyzer was lowered to water depths of 5 and $15 \mathrm{~m}$, respectively (Figure 5).) At each depth, the UWMS was 


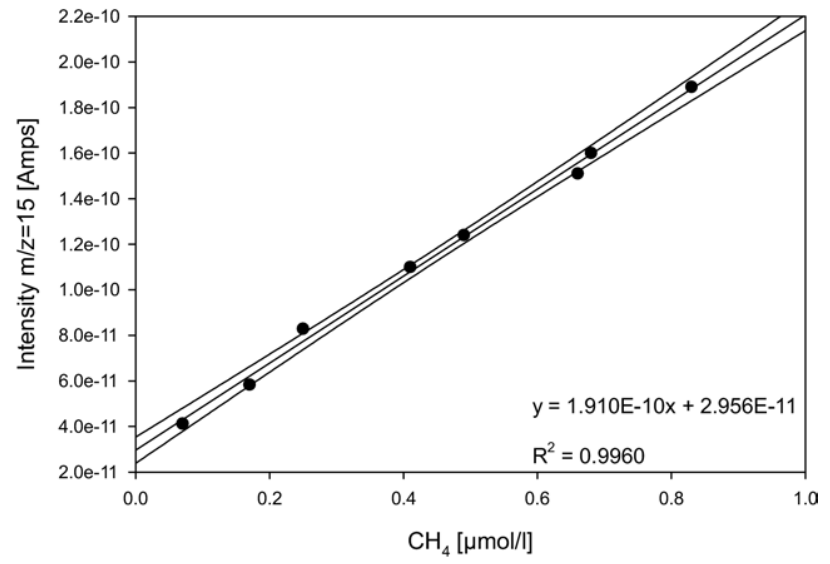

(a)

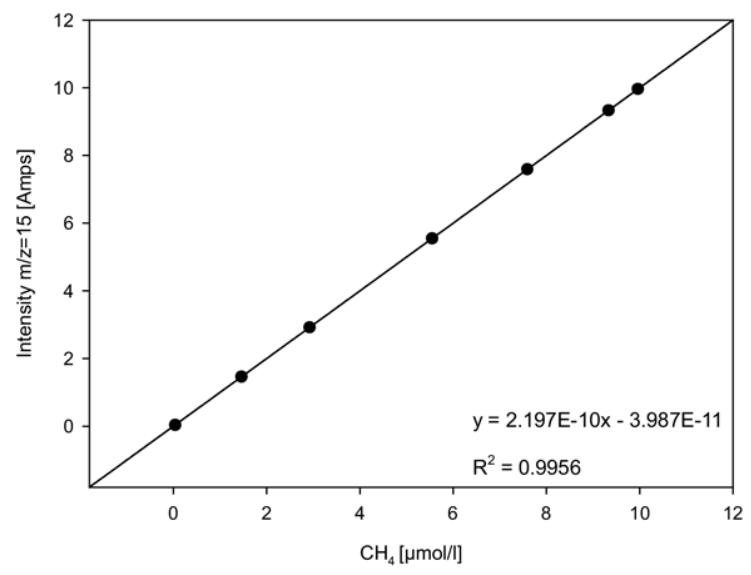

(b)

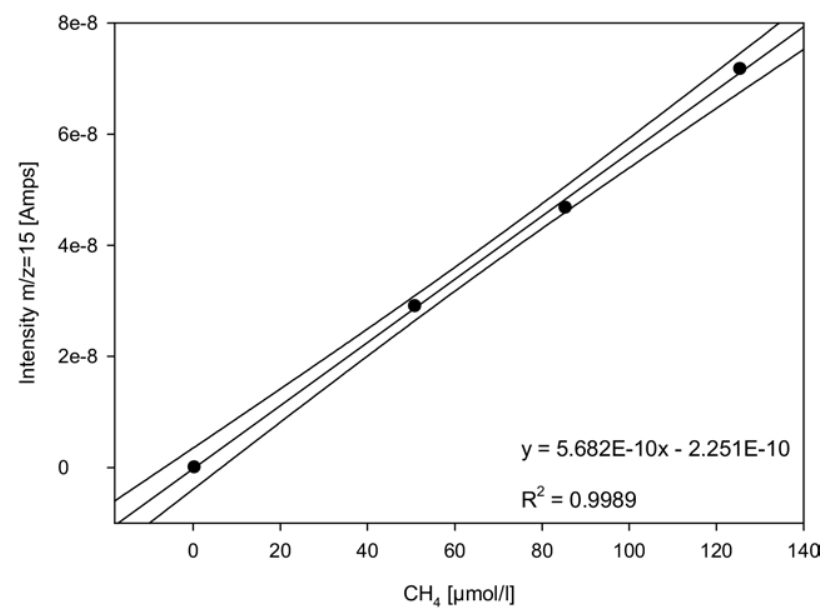

(c)

Figure 3. Calibration curves were derived by the MIMS (coupled with the cool-trap system) for (a) low, (b) medium, and (c) high methane concentrations. Based on the calibration curves and replicate measurements of methane free solutions, a detection limit of $16 \mathrm{nmol} / \mathrm{L}$ was computed. Besides the regression line, the $95 \%$ confidence intervals are also shown.

kept deployed for more than 10 to $15 \mathrm{~min}$ while the research vessel was drifting over possible discharge sites. These in situ measurements were applied before

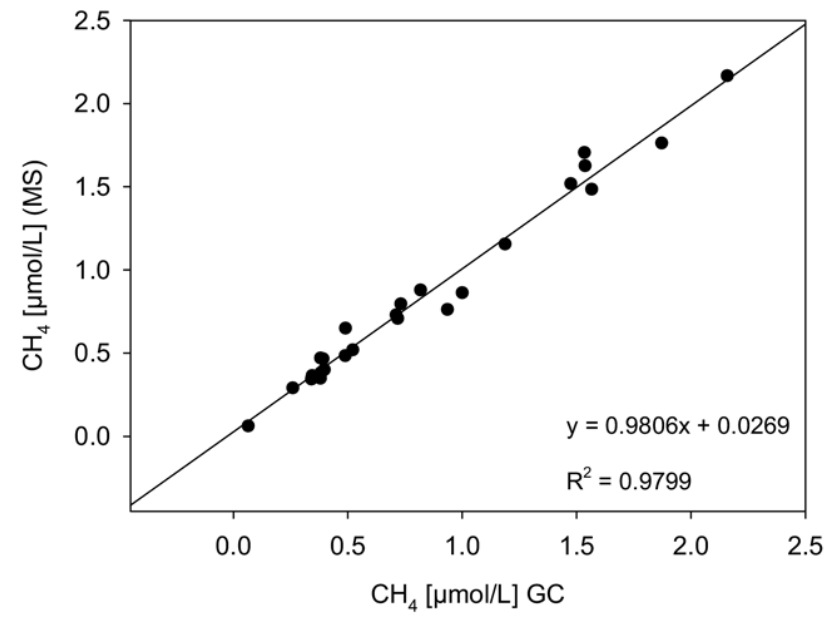

Figure 4. Comparison of $\mathrm{CH}_{4}$ concentrations of water samples analyzed by MIMS and gas chromatography during field studies on Lake Constance.

the design of the cool-trap, when the detection limit for $\mathrm{CH}_{4}$ was $>100 \mathrm{nmol} / \mathrm{L}$. Neither the Inspectr200-200, the solid-state $\mathrm{CH}_{4}$ analyzer, nor the optical $\mathrm{CH}_{4}$ sensor (Figure 1) detected any methane concentrations. This suggests that the methane concentrations in the bottom water are below the detection limit of each of these analyzers.

In contrast to the $\mathrm{CH}_{4}$ signal, significant differences in the carbon dioxide and oxygen content were observed for different water depths (Figure 5). Comparing the $\mathrm{CO}_{2}$ intensities measured in the air (onboard ship) with those observed in a water depth of 5 or $15 \mathrm{~m}$ reveals significant differences. The inverse relationship between the $\mathrm{CO}_{2}$ and $\mathrm{O}_{2}$ content with depths underlines the importance of the microbial degradation of organic matter for carbon dioxide enrichment in bottom waters.

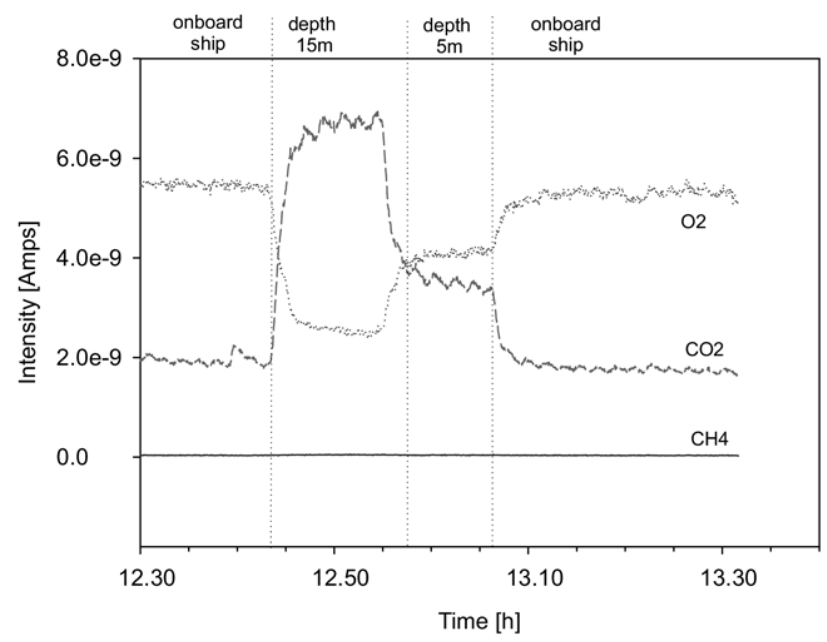

Figure 5. During a deployment of the Inspectr200-200, the content of $\mathrm{O}_{2}, \mathrm{CO}_{2}$, and $\mathrm{CH}_{4}$ were analyzed in 15 and $5 \mathrm{~m}$ water depth, respectively. 


\section{Continuous Online Measurements of $\mathrm{CH}_{4}$ and $\mathrm{CO}_{2}$ for Surface and Bottom Waters of Lake Constance}

In Lake Constance, the release of gas bubbles and gas flares emanating from the seafloor at pockmarks were observed during surveys with acoustic techniques such as echosounder and side scan sonar (M. Wessel, Institute for Limnic Research Langenargen, Germany). Whereas emanating gas flares can be easily visualized by acoustic techniques, chemical analysis is required for the quantification of gas concentrations. Due to the considerable spatial heterogeneity of the concentration field around discharge sites, the approach to obtain discrete water samples by Rosette Sampler or to apply spray chambers for shipboard analysis by GC is rather time-consuming and laborious.

During several cruises by the R. V. Kormoran we conducted online gas analysis for surface and bottom waters of Lake Constance by the Inspectr200-200. During these cruises, the Inspectr200-200 was combined with the cool-trap system and applied on board ship. For continuous online analyses, water samples were obtained by the surface water pump of the ship (the suction point is located $1.5 \mathrm{~m}$ below the water line). At pockmark sites, the submersible pump was applied to obtain continuously samples from water depths of e.g., $70 \mathrm{~m}$ while the ship was slowly crossing the pockmark site from different directions.

Methane concentrations measured in surface waters along transects from the harbor Langenargen to the pockmark site PM80 (located in $80 \mathrm{~m}$ water depth) and PM13 are shown in Figure 6. For surface waters of the pockmark site $\mathrm{CH}_{4}$ concentrations exceeding 500 nmol/L were observed. Furthermore, considerable horizontal variabilities are obvious at this site. Within short

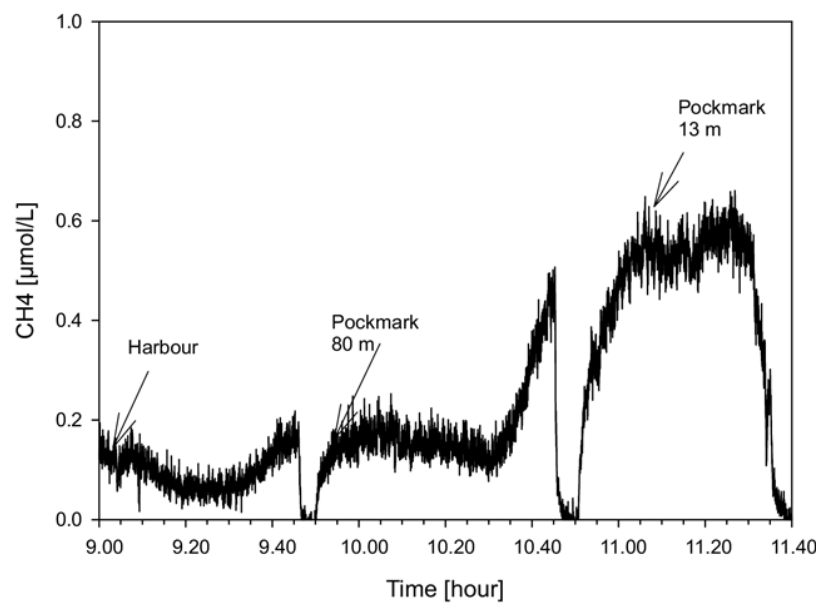

Figure 6. Methane concentrations in surface waters along the transect from the harbor to two pockmarks sites located in 80 and $13 \mathrm{~m}$ water depth, respectively. The data are unfiltered raw data. The arrows indicate the time when the sampling started in the harbor or at pockmarks. Before sampling at a new location, methane-free water was pumped over the membrane inlet for detection of the background intensity.

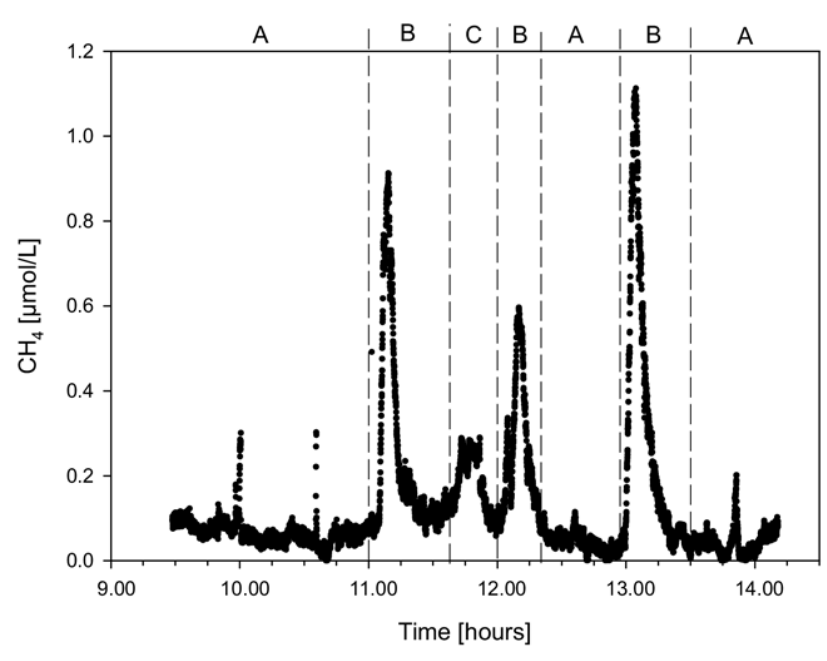

Figure 7. Methane measurements at the pockmark site PM80. Surface waters (a), samples derived by the submersible pump from a water depth of $70 \mathrm{~m} \mathrm{(b)}$, as well as samples obtained by the Rosette Water Sampler from depth of $70 \mathrm{~m}$ (c) were analyzed by the Inspectr200-200. The time spans samples were obtained from each water depth are indicated by the stipulated lines.

distance $\mathrm{CH}_{4}$ concentrations in surface water vary between 50 and $600 \mathrm{nmol} / \mathrm{L}$ (Figure 6, e.g., in the transition to PM13).

At the pockmark site PM80, where intense seepage of gas was observed by acoustic techniques, surface water samples were obtained by the intake system of the ship and from a water depth of $70 \mathrm{~m}$ by the submersible pump (Figure 7). During the continuous water sampling, the vessel was slowly drifting across the pockmark from different directions. In total an area of $90 \times 90 \mathrm{~m}$ was covered during this survey. Furthermore, discrete bottom water samples were gathered by a Rosette Sampler within the centre of the pockmark.

For water depths of $70 \mathrm{~m}$, high $\mathrm{CH}_{4}$ concentrations of more than 800 and $1100 \mathrm{nmol} / \mathrm{L}$ were measured (Figure 7, time spans B). Nevertheless, strong increases as well as decreases of methane concentrations were observed for a water depth of $70 \mathrm{~m}$ while the vessel was slowly crossing the pockmark. We assume that these small scale lateral variations are related to the occurrence of gas bubble streams released from the seafloor. Such gas bubble streams ascending to the sea surface were observed by visual inspection from ship as well as by scuba divers.

In addition to the continuous measurements, a water sample from a depth of $70 \mathrm{~m}$ was gathered by the Rosette Sampler and analyzed by the Inspectr200-200. Although the $\mathrm{CH}_{4}$ concentration of this bottom water sample revealed enhanced methane concentrations if compared to surface waters, the concentration is considerably lower than those obtained during the continuous measurements (Figure 7, time span B and C). Similar results were obtained at other discharge sites where methane concentrations of water samples obtained by the Rosette Sampler were always lower than 
those obtained by continuous sampling and analysis. We consider this as a result of the probabilistic approach linked to the discrete sampling by, e.g., Rosette Sampler, compared with the continuous sampling and analysis by MIMS. To cope with this, a considerable number of deployments of a water sampler, even within the rather small discharge site of $90 \times 90 \mathrm{~m}$, are required to obtain samples of more than $600 \mathrm{nmol} / \mathrm{L}$ $\mathrm{CH}_{4}$.

\section{Conclusions}

Investigations about the spatial distribution of trace gases in the water column are major topics for basic and applied research. This includes studies on biogeochemical cycles as well as applied research considering gas hydrates, $\mathrm{CO}_{2}$ sequestration or environmental monitoring of pipelines and production platforms. For several of these objectives online and in situ analysis (operating in water depths of several hundred meters) provides considerable improvements compared to analysis of discrete water samples transferred from depth to the research vessel for chemical analysis.

This is an important issue when distinct discharge locations are investigated where gases like methane are released from the seafloor. The short time required for gas analysis by MIMS combined with submersible pumps for continuous sample acquisition or the deployment of an underwater mass spectrometer allows detailed investigations of the concentration field around natural seeps or pipelines, for example.

Whereas the spatial pattern of the concentration field might be derived from peak intensities detected at selected mass-charge-ratios, a careful calibration is required for considerations of $\mathrm{CH}_{4}$ concentration and calculation of geochemical budgets. Especially for sea going cruises onboard small and medium sized research vessel, a calibration scheme is beneficial that does not require a complex apparatus. The simple volumetric admixture of two well-defined end member concentrations by a peristaltic pump is considered to be an inexpensive and accurate mode for calibration of MIMS.

Related to the specific objectives of basic or applied studies, the application of a cool-trap or the use membranes that are selective for specific compounds might be recommended. In case of investigations of methane discharge, the design of the cool-trap reduced interferences caused by water vapor content considerably, and improved the detection limit of the MIMS by a factor of five. Therefore, upcoming technical developments in the field of underwater mass spectrometry such as miniaturization of mass spectrometers or vacuum pumps might also consider the use of different types of membrane and separation techniques.

\section{Acknowledgments}

The authors thank the captain and crew of R. V Heincke and R. V. Kormoran for their assistance during the research cruises. The authors appreciate the scientific support by Dr. T. Wessels, Dr. I. Bussmann, and Erwin Hartmann during the sampling and analysis sessions. Many thanks go to Tim Short, Ryan Bell, and G. Kibelka for support and helpful discussions in the field of under water mass spectrometry.

\section{References}

1. Hovland, M; Judd, A. J. (1988). Seabed Pockmarks and Seepages. Graham and Trotman Limited, London.

2. Fleischer, P.; Orsi, T. H.; Richardson, M. D.; Anderson, A. L. Distribution of free gas in marine sediments: a global overview. Geo-Marine. Lett. 2001, 21, 103-122.

3. Milkov, A. V. Worldwide distribution of submarine mud volcanoes and associated gas hydrates. Mar. Geol. 2000, 167, 29-42.

4. Kvenvolden, K. A; Lorenson, T. D. (2001). The global occurrence of natural gas hydrate. In: Paull, C. K.; Dillon, W. D. (Eds.), Natural Gas Hydrates: Occurrence, Distribution, and Detection. Geophy. Monogr. 124: 3-18.

5. Wiesenburg, D. A.; Guinasso N. L. Jr. Equilibrium solubilities of methane, carbon monoxide, hydrogen in water and seawater. J. Chem. Eng. Data. 1979, 24, 356-360.

6. Weiss, R. F. Determinations of carbon dioxide and methane by dual catalyst flame ionization chromatography and nitrous oxide by electron capture chromatography. J. Chromatogr. Sci. 1981, 19, 611-616.

7. Weiss, R. F.; Van Woy, F. A.; Salameh, P. I. L. (1992). Surface water and atmospheric carbon dioxide observations by shipboard automated gas chromatography: Results from expeditions between 1977 and 1990 Scripps Institution of Oceanography, Environmental Sciences Division Publication No. 3987, SIO Reference 92-11.

8. Lammers, S.; Suess, E. An improved head-space analysis method for methane in seawater. Mar. Chem. 1994, 47, 115-125.

9. Lloyd, D.; Thomas, K.; Price, D.; O'Neil, B.; Oliver, K.; Williams, T. N. A membrane-inlet mass spectrometer miniprobe for the direct simultaneous measurement of multiple gas species with spatial resolution of $1 \mathrm{~mm}$. J. Microbiol. Methods. 1996, 25, 145-151.

10. Lloyd, D.; Thomas, K. L.; Cowie, G.; Tammam, J. D.; Williams, A. G. Direct interface of chemistry to microbiol. systems: membrane inlet mass spectrometr. J. Microbiol. Methods. 2002, 48, 289-302.

11. Benstead, J.; Lloyd, D. Spatial and temporal variations of dissolved gases $\left(\mathrm{CH}_{4} \mathrm{CO} 2\right.$, and. O2) in. peat. cores. Microbial. Ecol. 1996, 31, 57-66.

12. Sheppard, S. K.; Lloyd, D. Effects of soil amendment on gas depth profiles in soil monoliths using direct mass spectrometric measurement. Bioresource. Technol. 2002, 84, 39-47.

13. Yang, X.; Shang, C. Quantification of aqueous cyanogen chloride and cyanogen bromide in environmental samples by MIMS. Water. Res. 2005, 39, 1709-1718.

14. Tortell, P. D. Dissolved gas measurements in oceanic waters made by membrane inlet mass spectrometry. Limnol. Oceanogr. Methods 3, 2005, 2005, 24-37.

15. Hartnett, H. E.; Seitzinger, S. P. High-resolution nitrogen gas profiles in sediment porewaters using a new membrane probe for membrane-inlet mass spectrometry. Mar. Chem. 2003, 83, 23-30.

16. Short, R. T.; Fries, D. P.; Toler, S. K.; Lembke, C. E.; Byrne, R. H. Development of an underwater mass-spectrometry system for in situ chemical analysis. Meas. Sci. Technol. 1999, 10, 1195-1201.

17. Short, R. T.; Toler, S. K.; Kibelka, G. P. G.; Rueda Roa, D. T.; Bell, R. J. Byrne, R. H. Detection and quantification of chemical plumes using a portable underwater membrane introduction mass spectrometer. Trends. Anal. Chem. 2006, 25(7), 637-646.

18. Matz, G.; Kibelka, G.; Dahl, J.; Lennemann, F. Experimental study on solvent-less sample preparation methods-Membrane extraction with a sorbent interface, thermal membrane desorption application and purgeand-trap. J. Chromatogr. 1999, 830(2), 365-376

19. Hemond, H.; Camilli, R. NEREUS: "engineering concept for an underwater mass spectrometer." Trends. Anal. Chem. 2002, 21, 526-533.

20. Camilli, R.; Hemond, H. F. (2004). NEREUS/Kemonaut, a mobile autonomous underwater mass spectrometer. Trends. Anal. Chem. 2004, 23, 307-313.

21. Wenner, P. G.; Bell, P. G.; van Amerom, F. H. W.; Toler, S. K.; Edkins, J. E.; Hall, M. L.; Koehn, K.; Short, R. T.; Byrne, R. H. Environmental chemical mapping using an underwater mass spectrometer. Trends. Anal. Chem. 2004, 23, 288-295.

22. Kibelka, G. P. G.; Short, R. T.; Toler, S. K.; Edkins, J. E.; Byrne, R. H. Field-deployed underwater mass spectrometers for investigations of transient chemical systems. Talanta 2004, 64, 961-969.

23. Bell, R. J.; Short, R. T.; van Amerom, F. H. W.; Byrne, R. H. Calibration of an In Situ Membrane Inlet Mass Spectrometer for measurements of dissolved gases and volatile organics in seawater. Environ. Sci. Technol. 2007, 41, 8123-8128.

24. Schlüter, M.; Linke, P.; Suess, E. Geochemistry of a sealed deep-sea borehole on the Cascadia Margin. Mar. Geol. 1998, 148, 9-20. 
25. Lloyd, D.; Scott, R. I. Direct measurement of dissolved gases in microbiological systems using membrane inlet mass spectrometry. J. Microbiol. Methods. Vol. 1983, 1, 313-328.

26. Short, R. T.; Fries, D. P.; Kerr, M. L.; Lembke, C. E.; Toler, S. K.; Wenner, P. G.; Byrne, R. H. Underwater mass spectrometers for in-situ chemical analysis of the hydrosphere. J. Am. Soc. Mass. Spectrom. 2001, 12, 676-682.

27. Holmes, M. F.; Sansone Rust, T.; Popp, P. Methane Production, Consumption, and Air-Sea Exchange in the Open Ocean: An Evalu- ation Based on Carbon Isotopic Ratios. Global Biogeochem. Cycles 2000, 14(1), 1-10.

28. Middelburg, J. J.; Nieuwhenhuize, J.; Iversen, N.; Hogh, N.; DeWilde, H.; Helder, W.; Seifert, R.; Christof, O. Methane distribution in European tidal estuaries. Biogeochemistry. 2002, 59, 95-119.

29. Bange, H. W.; Bartell, U. H.; Rapsomanikis, S.; Andreae, M. O. Methane in the Baltic and North Seas and a reassessment of the marine emissions of methane. Global Biogeochem. Cycles 1994, 8, 465-480. 